\title{
A Dynamic Model of Strategic Allocation of Sovereign Wealth Funds
}

\author{
Kouakou Thiédjé Gaudens-Omer \\ Economics Department, Alassane Ouattara Bouaké University, Bouaké, Côte d'Ivoire \\ Email: omerkouakou77@yahoo.fr.
}

How to cite this paper: Gaudens-Omer, K.T. (2019) A Dynamic Model of Strategic Allocation of Sovereign Wealth Funds. Theoretical Economics Letters, 9, 155-171. https://doi.org/10.4236/tel.2019.91013

Received: November 10, 2018

Accepted: January 29, 2019

Published: February 1, 2019

Copyright $\odot 2019$ by author(s) and Scientific Research Publishing Inc. This work is licensed under the Creative Commons Attribution International License (CC BY 4.0).

http://creativecommons.org/licenses/by/4.0/

\begin{abstract}
This article draws on stylized facts to build a dynamic portfolio allocation model of sovereign wealth funds (SWF). We show that a traditional dynamic Merton allocation model allows for the stylized evidence that, on the one hand, the shares of monetary assets in such funds grow with the risk aversion of the state-investor in time, and on the other hand, these funds include the presence or absence of hedge funds correlated to the financial situation. One weakness of this model is its prediction of a lower risk/riskier asset ratio for sovereign stabilization funds and generational savings sovereign funds. This result contradicts the stylized fact of a lower risk/riskier asset ratio in stabilization funds than in generational savings funds. A dynamic model inspired by the theoretical framework of Bajeux-Besnainou et al. [1] is compatible with all the stylized facts.
\end{abstract}

\section{Keywords}

Sovereign Wealth Funds, Portfolio Management, Dynamic Portfolio Selection Model, Lifestyle Funds

\section{Introduction}

Sovereign wealth funds seem to be on the rise in Africa. The first African sovereign wealth fund (SWF) was created by Ghana in 1993. African countries managed nearly $\$ 156$ billion at the end of May 2013. Nearly 22 sovereign wealth funds exist in Africa and still others are in the pipeline. With more than $\$ 65$ billion in assets, the Libyan fund is the largest African sovereign wealth fund. In sub-Saharan Africa, Angola and Nigeria are at the top of the ranking of the largest sovereign wealth funds. Other countries such as Gabon and Equatorial Guinea have sovereign wealth funds. Senegal, which has very few natural resources, has launched its sovereign wealth fund. The IMF (International Monetary Fund) 
defines sovereign wealth funds as government-owned and purpose-built investment funds. Created by a public authority for macroeconomic management purposes, SWFs hold, manage or administer assets to achieve financial objectives and use a series of investment strategies that include investments in foreign financial assets. Clearly, sovereign wealth funds are long-term public investment funds with no liability, which are at least partially invested in foreign assets [2] [3].

Sovereign wealth funds are usually created from balance of payments surpluses, foreign exchange transactions, proceeds of privatization, budget surpluses and/or revenues from commodity exports. The decision to create a sovereign wealth fund responds to clearly identified macroeconomic needs. Sovereign wealth funds around the world have grown rapidly, and according to the SWF Institute, the total amount of the 67 national funds was $\$ 5402$ billion in 2013. This value has almost doubled over the last decade. Arab oil-producing Gulf countries have created the first sovereign wealth funds. Far behind Asia (40\%) and the Middle East (35\%), Africa accounts for only $3 \%$ of sovereign fund volumes collected by governments around the world. In general, countries that create sovereign wealth funds are those who live off the wealth of their commodity and mineral exports. The objective of these countries is to take advantage of the manna of exporting raw materials to stabilize the country's economy and boost its development (Thouraya Triki and Issa Faye).

There are two main categories of sovereign wealth funds: stabilization funds and generational savings funds. Stabilization funds help to preserve energy security and promote the economic and social development of countries [4] [5]. They also act as lenders of last resort or insurance funds in the context of crises and financial turmoil [2] [3]. Stabilization funds have a medium-term horizon and will tend to invest in liquid assets and relatively less risky asset classes. Generational savings funds are a kind of precautionary savings when there is uncertainty about the future of future generations. These savings funds for future generations have a long-term horizon and will invest in relatively riskier asset classes with higher returns. These two types of sovereign wealth funds, however, raise many questions as to their purpose, according to the African Development Bank (ADB): are they aimed exclusively at economic stabilization and intergenerational savings? Such a question is all the more justified because some African sovereign wealth funds also seem to be used as "slush funds" in which governments regularly draw money. Political factors may override profitability considerations, creating a bias in the investment policy of these funds. But beyond this governance problem, the biggest challenge facing African sovereign wealth funds is structural. Indeed, most of these funds suffer from a size that is often too small and with too little liquidity. In addition, these funds often invest in sovereign debt (sometimes their own country) badly rated and the markets on which they invest are too fragmented.

In general, African sovereign wealth funds are characterized by a lack of 
transparency as to their investment strategies and performance. The details of the investments are not very transparent, but the known figures suggest that they invest in money and bonds as well as outside Africa. African SWFs seem to be suffering from a lack of investment technology and portfolio management expertise. This raises the question of the best investment strategy of sovereign wealth funds. What should an optimal investment strategy for sovereign wealth funds look like? To answer this problem, we use the methodology of theoretical modeling. The rest of the article is organized as follows: Section 2 reviews the literature on the strategic allocation of SWFs and some stylized facts useful for the theoretical model. In Section 3, we develop a dynamic model of allocation of sovereign funds without and with portfolio revision, according to the analytical framework of Merton as well as that of Bajeux-Besnainou et al. [1]. Section 4 concludes the article.

\section{Literature Review and Stylized Facts}

\subsection{Strategic Allocation of Sovereign Wealth Funds: A Literature Review}

Sovereign wealth funds have various economic objectives, such as stabilizing the budget, diversifying resources, saving for future generations. They also pursue political strategy goals, such as controlling politically sensitive industries or supporting the domestic economy (Avendano and Santiso, 2009; Ang, 2012). Sovereign wealth funds can be managed by different institutional structures, such as central banks or independent financial institutions. Having the status of public institutional investor (IMF, 1978), sovereign wealth funds are primarily managed funds according to proven investment strategies despite macroeconomic objectives pursued and the presence of states.

Sovereign wealth funds prioritize strategic allocation as an allocation strategy. The strategic asset allocation, which has a long horizon (several years), concerns a small number of asset classes (equities, bonds and money market securities) and depends on the risk aversion and the wealth of the investor. For example, the asset allocation of the Norwegian fund is: $40 \%$ bonds, $60 \%$ equities; the asset allocation of the Singaporean GIC fund is: $30 \%$ bonds, $50 \%$ shares, $20 \%$ alternative. According to the IMF, nearly $40 \%$ of sovereign wealth funds invest in private equity or real estate. The majority of Sovereign Wealth Fund assets are invested in listed securities, with a recent strong trend in hedge funds (private equity). At the sector level, most SWFs focus on finance, real estate and new technologies.

The literature on the management of sovereign wealth funds often considers the medium and long-term management of sovereign wealth funds (stabilization funds, generational savings funds). Such management combines strategic asset allocation and tactical asset allocation. The strategic asset allocation, which has a long horizon (several years), concerns a small number of asset classes (equities, bonds and money market securities) and depends on the risk aversion and 
wealth of the investor; the tactical allocation with a short horizon (less than six months) does not depend on the investor's utility function but focuses on individual securities; it is a bet on the investor's ability to take advantage of opportunities or to anticipate market reversals. A rational allocation process can combine the strategic allocation that first fixes the investments by major asset classes and the tactical allocation that then makes it possible to choose the different individual securities and their weights, under the previously defined constraints by the strategic allocation.

Mathis [6] proposes to distinguish three phases in the choice of portfolio. The first phase, called strategic, leads to specify the market segment that will serve as benchmark for the fund. This is most often a market index. This decision is made prior to the formation of the fund and is generally not the responsibility of the manager. The so-called tactical second phase specifies the fund's expected benchmark objectives: is it to replicate the index, outperform it or only to a benchmark? Finally, the third step is the actual selection of the securities to meet the profitability objectives set out in the fund. The manager intervenes only in the last two stages. Aaron, Bilon, Galanti and Tadjeddine [7] defined management styles through three elements: the presence or absence of a referent; the nature of the referent's influence; the existence of conditions when selecting securities.

The strategic allocation takes into account the characteristics of the investor (age, attitude to risk) and most often concerns long-term investments. It consists of three rules: the first dictates the distribution of weights in each of the three major categories of financial securities: monetary assets ( $\leq 1$ year); bonds (5 - 10 year fixed rate fund); equities (stock index or predetermined portfolio). This composition of the portfolio depends on the investor's objectives (which depend on his wealth and risk aversion) and on the duration (T) of the investment. The second rule determines the evolution of these weights (buying or selling risky securities) according to the time elapsed or the age of the investor. The third rule dictates changes in the portfolio according to market developments (interest rate, stock market index). In general, in the trade, there is a consensus, based on common sense, for the first two rules while opinions diverge for the third.

A body of empirical research has analyzed the public investment strategies of sovereign wealth funds and their performance. Although these studies focus only on a fraction of sovereign wealth funds, mainly those investing in the shares of listed firms, they show that sovereign wealth funds tend to invest in large foreign companies, often in the financial, energy and investment sectors, with poor diversification and poor medium-term performance [8] [9] [10] [11]. The work of Bortolotti [11] shows that, in the medium and long term, or even the very long term, sovereign wealth funds seek the greatest security in the face of economic cycles and regional events. They privilege the performance-safety pair compared to risky investments, which they do not necessarily control. In addition, a significant portion of the financial portfolio is invested in assets denominated in for- 
eign currencies. In addition, Sovereign Wealth Funds very often intervene far from their country of origin, in legal and economic contexts that they do not master without the assistance of advice; this drives them to look for investments that require little "asset management".

They favor the so-called "buy and hold" long-term management (no short-term round trips on financial securities). Their objective must be the maximization of the return on capital invested, unlike the central bank which manages capital in the interests of stability and not of profitability. In doing so, they do not suffer the short-term pressure of withdrawing funds in crisis episodes and are not constrained in their strategy by frictions of prudential regulation. Due to this long-term management, the performance of sovereign wealth funds can hardly be evaluated in the interim period. Sovereign wealth funds have also been used as "investors of last resort" during recent crises, intervening to support domestic financial markets [2] [3] [12].

A large portion of Sovereign Fund investments remain private and several works focus on funds investing in the shares of listed companies. Dyck and Morse [10] and Bernstein et al. [8] show that sovereign wealth portfolios tend to be insufficiently geographically diversified, with a strong domestic bias. Sovereign wealth funds tend to have significant shares in large companies in politically sensitive industries, such as energy, finance, telecommunications [9] [11], contradicting the principles of diversification (sound diversification). They also tend to take large shares in companies with financial difficulties, both abroad and in the country [2] [3]. The performance of these investments is generally poor in the long run, even though the announcement of SWF investments gives positive abnormal returns on the stock prices in the very short term [11].

\subsection{Theoretical Models of Optimal Allocation of Sovereign Funds}

Theoretical work on the optimal management of sovereign funds is rare. Some studies focus on the allocation of sovereign funds whose resources come specifically from certain commodities. Thus, Scherer [13] [14], Brown et al. [15], and Martellini and Milhau [16] study the optimal allocation of a sovereign wealth fund by examining the wealth of non-tradable assets in the fund (the fund's paper oil assets) or exogenous liabilities, of which a proxy is the index indexed to inflation. But the example of recent crises clearly shows that other sovereign liabilities must be taken into account: debt, contingent liabilities, and so on. In addition, when a government runs out of liquidity to pay its debts, sovereign wealth fund assets are often available to replace funds originally earmarked for this purpose. In 2010, in the middle of the subprime crisis, Russia, Ireland, Kazakhstan and Qatar used their sovereign funds or public pension funds to invest in banks or support the stock markets.

The best theoretical models for optimal allocation of SWFs seem, to our knowledge, those developed by Bodie and Brière [17] [18] [19]. In their model, the sovereign is taken in a broader sense, including all related institutions 
(budget government, central bank, sovereign wealth funds, pension funds, etc.). Managing the wealth of a state is not much different from managing an individual's wealth [17] [18] [19], a pension fund's wealth [17] [18] [19] or a foundation's wealth [20]. Knowing how much should be saved and how wealth should be invested is a classic asset-liability management problem (ALM problem), the optimal allocation and spending depend crucially on the nature and size of the assets and liabilities, and the sources of their uncertainty. Merton [20] solved a similar problem for a university endowment fund.

Bodie and Brière [17] [18] [19] propose to estimate the state's economic balance sheet by using the theory of contingent claims and considering the joint management of all sovereign assets and liabilities in an asset-liabilities management framework. In this sovereign case, the optimal allocation differs slightly. They assume that the objective of the state is to maximize its expected utility, which is a function of its overall sovereign surplus "Global Sovereign Surplus (GSS)", dependent on the allocation of the sovereign's assets. Bodie and Brière [17] [18] [19] show how the question of the optimal allocation of sovereign funds can be considered globally as a classic asset-liability management problem. Indeed, tax revenues that the central government receives each year; a portion is used as operating expenses, investment and to repay external and domestic debts. The residue is saved in a sovereign wealth fund, in central bank reserves or in the public pension fund.

The optimal allocation of the sovereign wealth fund depends crucially on the nature and size of the sovereign's assets and liabilities, and the sources of their uncertainty. Bodie and Brière [17] [18] solve this problem analytically and show that the optimal portfolio consists of a portfolio seeking performance and three additional portfolios covering the variability of fiscal surplus and external and domestic debt. Bodie and Brière [19] generalize these results by introducing other sources of risk affecting the sovereign's balance sheet: inflation [16], changes in oil prices [13] [14], etc. In a more general context, taking into account all the sources of risk affecting the sovereign's balance sheet, three terms of demand for cover are added to the speculative portfolio. They take into account not only the risks of inflation and commodity price fluctuations (which affect the variability of the tax surplus) but also the risks arising from foreign and domestic liabilities. In addition, the variability of the fiscal surplus is influenced not only by commodity prices and the volatility of inflation, but also by the sovereign's policies on natural resource extraction, taxation, and so on.

In a nutshell, the optimal portfolio of sovereign funds consists of a speculative portfolio seeking performance and three additional portfolios that hedge the risks affecting the sovereign's balance sheet (fluctuations in commodity prices, volatility of inflation, risks arising from foreign and domestic liabilities, political risk related to the sovereign's policies on extraction of natural resources, taxation, etc.).

These theoretical models make it possible to provide advice for the management of sovereign wealth funds, taking into account the relationship between 
sovereign wealth funds and foreign exchange reserves. The optimal composition of the sovereign wealth fund should involve a portfolio seeking performance and three hedge portfolios due to the variability of the fiscal surplus and external and internal debt. Thus, the models of Bodie and Brière [17] [18] [19] revisit the issue of the management of sovereign wealth funds, considering all sources of public revenues and public expenditures (public institutions, central bank, sovereign wealth funds, investment funds, pension funds, etc.). In doing so, they shed new light on the question of the optimal allocation of the sovereign fund.

But one limitation of these models is that they do not explain the difference in optimal allocation between sovereign stabilization funds and generational savings sovereign funds. Indeed, stabilization funds that have a medium-term horizon tend to invest in liquid assets and relatively less risky asset classes; and generational savings funds with a long-term horizon tend to invest in relatively riskier asset classes with higher returns. The ratio of riskier assets to less risky assets is therefore lower in stabilization funds than in generational savings funds. Thus, the portion of risk-free assets (monetary assets, for example) in the sovereign fund portfolio differs according to the risk profile of the fund. Such a fact appears immediately in accordance with the allocation rule in this case is governed by the two-fund separation theorem of Tobin-Black-Markowitz. However, Markowitz's theoretical model is a static model that is not compatible with the long-term horizon that sovereign wealth funds aim at. Modeling the allocation of sovereign wealth portfolios requires the use of dynamic portfolio optimization models.

The first dynamic models of portfolio management were developed by Samuelson [21] and Merton [20]. The purpose of these models is not necessarily to achieve an efficient portfolio in the mean-variance sense, but more generally to maximize the expectation of usefulness of the terminal value of the portfolio. Efficient portfolios are obtained by maximizing the expectation of a quadratic utility function, a very special case of a class of utilities called Hyperbolic Absolute Risk Aversion (HARA). We model the allocation of SWFs via a dynamic, continuous-time model based on stochastic dynamic programming. The great complexity of stochastic dynamic programming may limit its practical application [22]. Only in very specific cases such as the use of CRRA utility functions or complete financial markets [23] [24] can one obtain a simple analytical solution of optimal dynamic strategy

\subsection{Some Stylized Facts}

Before developing the theoretical model that describes the optimal allocation of sovereign funds, we identify the stylized facts that attempts to reproduce the modeling. These stylized facts (SF) highlight knowledge gained from previous work or management practices of SWFs.

$\checkmark$ FS1: There are two main categories of sovereign wealth funds: stabilization funds and generational savings funds. Stabilization funds have a medium-term 
horizon and will tend to invest in liquid assets and relatively less risky asset classes. Generational savings funds have a long-term horizon and will invest in relatively riskier asset classes with higher returns.

$\checkmark$ FS2: Sovereign fund managers who manage stabilization funds are more risk-averse than those who manage generational savings funds. This principle is based on theoretical results from precautionary savings models, intertemporal smoothing, etc. This allows risk profiles of sovereign wealth funds to be defined in the absence of risk aversion indicators.

$\checkmark$ FS3: It can be seen that in the practice of managing SWFs, the allocation of the risky fund (equities, bonds, real estate shares, land shares, etc.) is a function of the risk profile of the manager, the State-investor.

$\checkmark$ FS4: In sovereign wealth funds, the share of monetary assets depends on the risk profile of the fund managers who adapt to the risk profile of the country owning the fund. Indeed, stabilization funds that have a medium-term horizon tend to invest in liquid assets and relatively less risky asset classes; and generational savings funds with a long-term horizon tend to invest in relatively riskier asset classes with higher returns. The ratio of riskier assets to less risky assets is therefore lower in stabilization funds than in generational savings funds.

$\checkmark$ FS5: Some sovereign wealth funds have hedge funds in their assets, while others do not.

We model, in the next section, the allocation of sovereign funds, which reproduces these stylized facts above.

\section{Modeling the Allocation of Sovereign Funds}

\subsection{A Dynamic Sovereign Fund Allocation Model with Portfolio Revision}

The objective of the sovereign wealth fund is to maximize the expected utility of the terminal value $X(T)$ of the investment. To achieve this objective, the sovereign fund manager implements a dynamic portfolio strategy that consists of determining, at all times, the proportions of the fund available to allocate to each of the available financial securities: instantaneously risk-free assets, and various risky assets (bonds, shares, real estate or land, etc.). The sovereign wealth fund has an initial investment of amount $X(0)=X_{0}$. This initial fund has a certain rate of return $R_{t}$ over the period $(0, T)$. Unlike the dynamic model without revision, the dynamic model with revision integrates a vector $\underline{Y}(t)$ of state variables characterizing the financial situation (interest rate, stock market index, etc.). It is the changing nature of the economic and financial situation that allows for a possible revision of the sovereign fund portfolio.

The sovereign fund manager is supposed to consider only self-financing strategies, with no contributions or withdrawal of funds between 0 and $T$ and bearing negligible management costs. It is considered that there are $N+1$ assets (denoted $0,1, \cdots, N$ ) exchanged on the market supposed to be open conti- 
nuously. Asset 0 is risk free in the very short term (in all $t$, on the horizon $t+\mathrm{d} t$ ) while assets $1, \cdots, N$ are risky. At a time $t$, a portfolio is defined, to a scale factor, by the weights $\alpha_{1}(t), \cdots, \alpha_{N}(t)$ of the $N$ risky securities. The weight $\alpha_{0}(t)$ of the asset instantaneously without risk is therefore equal to:

$$
\alpha_{0}(t)=1-\sum_{i=1}^{N} \alpha_{i}(t) \Rightarrow x_{0}(t)=1-\underline{1}^{\prime} \underline{x}(t)
$$

Noting $S_{i}(t)$ the price of the asset $i$ in $t, r(t)$ the short rate (stochastic) and $\mathrm{d} R_{i}(t)$ the random profitability of the title $i$ between $t$ and $t+\mathrm{d} t$, it comes:

$$
\frac{\mathrm{d} S_{0}}{S_{0}}(t)=r(t) \mathrm{d} t ; \frac{\mathrm{d} S_{i}}{S_{i}}(t) \equiv \mathrm{d} R_{i}(t), i=1, \cdots, N
$$

The vector of $N$ risky returns is noted $\mathrm{d} \underline{R}$ and presumed to evolve according to a multidimensional Itô process:

$$
\mathrm{d} \underline{R}=\underline{\mu}(t) \mathrm{d} t+\Sigma(t) \mathrm{d} \underline{W}
$$

It is assumed that the $N$ risky assets are non-redundant, which implies that the variance-covariance matrix $V(t)$-of general term $v_{i j}\left(v_{i j} \mathrm{~d} t=\operatorname{Cov}\left(\mathrm{d} R_{i}, \mathrm{~d} R_{j}\right)\right)$ with $V(t)=\Sigma^{\prime}(t) \Sigma(t)$-is invertible. The portfolio strategy $\underline{\alpha}(t)$ and the initial investment $X(0)$ normalized to 1 are combined with the value of the portfolio $X(t)$. We will note later this strategy, $(\underline{\alpha}, X)$. The relative change in value of a self-financed portfolio corresponds to its profitability, equal to the weighted sum of the returns of its components:

$$
\begin{gathered}
\frac{\mathrm{d} X}{X}=\alpha_{0}(t) r(t) \mathrm{d} t+\underline{\alpha}^{\prime}(t) \mathrm{d} \underline{R}=\left[1-\underline{1}^{\prime} \underline{\alpha}(t)\right] r(t) \mathrm{d} t+\underline{\alpha}^{\prime}(t) \mathrm{d} \underline{R} \\
\frac{\mathrm{d} X}{X}=r(t) \mathrm{d} t+\underline{\alpha}^{\prime}(t)(\mathrm{d} \underline{R}-r(t) \underline{1} \mathrm{~d} t)
\end{gathered}
$$

As before, we assume that the objective function of the sovereign fund manager is the expected utility of the terminal value, i.e. $E\{U(X(T))\}$. Always consider that the utility function is of the CRRA type (Constant Relative Risk Aversion). But we choose a logarithmic utility function for which the risk aversion coefficient is constant (CRRA) and equal to 1 :

$$
U(X(T))=\ln (X(T))
$$

The manager of the sovereign wealth fund with such a logarithmic utility function is called a logarithmic investor. This assumption about the manager's preferences reflects the idea that he is short-sighted, that is, he does not have to worry about what will happen in later periods. To see this, it suffices to show ${ }^{1}$ that $\ln (X(T))=\ln (X(0))+\sum_{t=1}^{N} \ln \left(R_{t}\right)$. In this case, maximizing $E\{\ln (X(T))\}$ is equivalent to maximizing $\sum_{t=1}^{N} E\left\{\ln \left(R_{t}\right)\right\}$. Therefore, the choice of portfolio in $\mathrm{t}$ does not affect the rates of return that can be obtained in subsequent periods

${ }^{1} X(T)=X(0) \frac{X(1)}{X(0)} \frac{X(2)}{X(1)} \cdots \frac{X(T)}{X(T-1)}=X(0) R_{1} R_{2} \cdots R_{N} \Rightarrow \ln (X(T))=\ln (X(0))+\sum_{t=1}^{N} \ln \left(R_{t}\right)$ 
$t+1, \cdots, N$. The maximization is thus obtained simply by the choice, at each step $t$, of the portfolio which ensures the maximization of $E\left\{\ln \left(R_{t}\right)\right\}$, without taking into account the $\ln \left(R_{i}\right)$ relating to the subsequent periods $t^{\prime}$ which will be maximized. when the time comes $t^{\prime}$. Such myopia greatly facilitates the calculation of the weights assigned to $\underline{\alpha}(t)$ risky securities.

A strategy can therefore be represented by a function $f$ giving, at any moment, the weights $\underline{\alpha}(t)$ attributed to the different assets. This allocation of the fund depends on the objectives of the investor (utility function), the elapsed time $t$ (between 0 and $T$ ), its wealth $(X(t))$ and a vector $\underline{Y}(t)$ of state variables characterizing the financial situation (interest rate, stock market index, etc.):

$$
\underline{\alpha}(t)=f(t, X(t), \underline{Y}(t) ; U, T)
$$

The manager of the sovereign fund chooses its self-financing strategy in order to maximize the expectation of the utility of the terminal value of its portfolio:

$$
\left\{\begin{array} { l l } 
{ \operatorname { M a x } _ { \underline { \alpha } } E \{ \operatorname { l n } ( X ( T ) ) \} } & { ( C _ { 1 } ) } \\
{ s c \frac { \mathrm { d } X } { X } = \alpha _ { 0 } ( t ) r ( t ) \mathrm { d } t + \underline { \alpha } ^ { \prime } ( t ) \mathrm { d } \underline { R } } & { ( C _ { 2 } ) } \\
{ X ( 0 ) \equiv X _ { 0 } = 1 }
\end{array} \Rightarrow \left\{\begin{array}{l}
\operatorname{Max}_{\underline{\alpha}, X} E\{\ln (X(T))\} \\
s c \frac{\mathrm{d} X}{X}=r \mathrm{~d} t+\underline{\alpha}^{\prime}(t)(\mathrm{d} \underline{R}-r \mathrm{~d} t \cdot \underline{1}) \\
X(0)=1
\end{array}\right.\right.
$$

This program is solved using stochastic dynamic programming, in the manner of Merton:

$\operatorname{Max}_{\underline{\alpha}(t)} E\{\ln (X(t+\mathrm{d} t))\} \Leftrightarrow \operatorname{Max}_{\underline{\alpha}(t)} E\{\mathrm{~d} \ln (X(t))\} \Leftrightarrow \operatorname{Max}_{\underline{\alpha}(t)} E\left\{\frac{\mathrm{d} X}{X}-\frac{1}{2}\left(\frac{\mathrm{d} X}{X}\right)^{2}\right\}$

according to Itô's lemma. Under $\left(C_{1}\right)$ we have:

$$
\begin{gathered}
\Leftrightarrow \operatorname{Max}_{\underline{\alpha}(t)} E\left\{\left(1-\underline{\alpha}^{\prime} \underline{1}\right) r \mathrm{~d} t+\underline{\alpha}^{\prime} \mathrm{d} \underline{R}-\frac{1}{2} \operatorname{variance}\left(\underline{\alpha}^{\prime} \mathrm{d} \underline{R}\right)\right\} \\
\Leftrightarrow \operatorname{Max}_{\underline{\alpha}(t)} E\left\{\underline{\alpha}^{\prime}(\underline{\mu}-r \underline{1})-\frac{1}{2} \underline{\alpha}^{\prime} \boldsymbol{V} \underline{\alpha}\right\} \Rightarrow \underline{\alpha}(t)=\boldsymbol{V}^{-1}(t) \cdot(\underline{\mu}-r \underline{1})
\end{gathered}
$$

This portfolio solution is called the Cash Portfolio (Long, 1990), Optimal Growth Portfolio [20] or Logarithmic Portfolio. The portfolio $(\underline{\alpha}, X)$ has several properties:

$\checkmark$ At each moment $t$, it is efficient on the horizon $t+\mathrm{d} t$. He is therefore homothetic to the tangent portfolio.

$\checkmark$ It maximizes the expected rate of growth of wealth at any time $T$.

The optimal growth portfolio $(\underline{\alpha}, X)$ dominates over the long term all other portfolios in the following direction: Whatever the feasible and self-financing portfolio strategy different from $(\underline{\alpha}, X)$ whose terminal value is $X(T)$, the probability of the event $[X(T)>Z(T)]$ tends to 1 when $T$ tends to infinity.

This property gave rise to Kelly's criterion, which is popular among some practitioners. According to this criterion, any investor whose horizon is distant should follow the logarithmic strategy since the probability that the value of his portfolio is greater than that he would obtain following a different strategy is, 
asymptotically, equal to 1 . In fact, this criterion applies only to the logarithmic investor. Indeed, we can show that $\lim _{T \rightarrow \infty} P[X(T)>Z(T)]=1$ does not imply $E\{U(X(T))\}>E\{U(Z(T))\}$ for all $U$ and for $T$ sufficiently large. Therefore, Kelly's criterion is inconsistent with the principle of maximizing the expectation of utility and in that sense is without foundation.

Like Merton, it is further assumed that the interest rate $r$ and the prices of the securities follow diffusion processes which depend on m state variables $\underline{Y}(t)$ themselves governed by diffusion processes. :

$$
\begin{gathered}
\mathrm{d} r=\phi(t, \underline{Y}) \mathrm{d} t+\underline{q^{\prime}}(t, \underline{Y}) \mathrm{d} \underline{W} ; \quad \mathrm{d} \underline{R}=\underline{\mu}(t, \underline{Y}) \mathrm{d} t+\Sigma(t, \underline{Y}) \mathrm{d} \underline{W} ; \\
\mathrm{d} \underline{Y}(t)=\underline{\alpha}(t, \underline{Y}) \mathrm{d} t+\boldsymbol{\Omega}(t, \underline{Y}) \mathrm{d} \underline{W}
\end{gathered}
$$

$\boldsymbol{\Omega}$ is a $(p \times m)$ matrix, $\boldsymbol{\Sigma}$ is a $(n \times m)$ matrix, $\underline{\alpha}$ and $\underline{q}$ are respectively vectors $m$ and $n$ dimensional. The resolution of this complex model leads to precise analytic relations only in very particular cases concerning processes and utility functions. Nevertheless, we get the general shape for optimal weights: $\underline{\alpha}^{*}(t, X, \underline{Y})=\tau(t, X, \underline{Y}) \underline{\alpha}(t, X, \underline{Y})+\sum_{k=1}^{m} \xi_{k}(t, X, \underline{Y}) \underline{\alpha}_{k}(t, X, \underline{Y})$ and $\alpha_{0}=1-\underline{\alpha}^{*} \underline{1}(7)$ where $\tau=-\frac{J_{X}}{X J_{X X}}$ represents the relative risk tolerance calculated in $\mathrm{t}$ from the indirect utility function; $\underline{\alpha}=\boldsymbol{V}^{-1}(\underline{\mu}-r \underline{1})$ is the optimal growth portfolio studied previously, with:

$$
\underline{\alpha}^{*}(t, X, \underline{Y})=-\frac{J_{X}}{X J_{X X}}\left(\Sigma^{\prime}(t) \Sigma(t)\right)^{-1}(\underline{\mu}-r \underline{1})+\sum_{k=1}^{m} \xi_{k}(t, X, \underline{Y}) \underline{\alpha}_{k}(t, X, \underline{Y})
$$

and $\alpha_{0}=1-\underline{\alpha}^{*} \underline{1}$

The expression $\left(\Sigma^{\prime}(t) \Sigma(t)\right)^{-1}(\underline{\mu}-r \underline{1})$ translates in vector form the ratio between the Sharpe ratio of the portfolio of the sovereign wealth fund and the volatilities of risky assets.

$$
\left(C_{1}\right) \Rightarrow \frac{\mathrm{d} X}{X}=\left[r(t) \mathrm{d} t+\underline{\alpha}^{\prime}(t)(\underline{\mu}(t)-r(t) \underline{1})\right] \mathrm{d} t+\underline{\alpha}^{\prime}(t) \Sigma(t) \mathrm{d} \underline{W} \quad\left(C_{1}^{\prime}\right)
$$

$\xi_{k}$ depends on the indirect utility function and reflects its sensitivity to the state variable $Y_{k}$. State variables influence investment prospects, including profitability expectations and risks, hence future differentiable utilities, and hence the indirect utility function; the evolution of a state variable can, in this sense, be favorable or unfavorable. $\underline{\alpha}_{k}$ is a portfolio whose profitability is perfectly correlated with the variable $\mathrm{d} Y_{k}$ of the kth state variable in the interval $[t, t+\mathrm{d} t]$ (and decorrelated with $\mathrm{d} Y_{j}$ ); the position on $\underline{x}_{k}$ is a hedge designed to protect the investor from the risk of an unfavorable evolution of $Y_{k}$.

Formally, the optimal share of the market portfolio is the weighted sum of $(m+1)$ factors: a proportion $\underline{\alpha}(t, X, \underline{Y})$ related to the risk profile of the manager and weighted by the degree of relative risk aversion of the manager, $-\frac{J_{X}}{X J_{X X}} ; m$ proportions $\underline{\alpha}_{k}(t, X, \underline{Y}), k=1, \cdots, m$, related to the sensitivity of the manager's preference to the state variable $Y_{k}, k=1, \cdots, m$ and each weighted by 
the sensitivity of the manager's indirect utility function to the state variable, $\xi_{k}(t, X, \underline{Y})$.

The expression of the optimal part of the market portfolio in the sovereign fund, in the event of portfolio revision, reflects the intuitive idea that it depends not only on the risk profile of the manager (as in the case without portfolio revision) but also on the sensitivity of its preferences to changes in the economic and financial situation. The optimal allocation of the sovereign fund wealth between the monetary asset and the market portfolio is revised when the economic and financial situation changes.

The optimal share of the market portfolio in the sovereign fund, in case of portfolio revision, depends on the risk aversion of the manager, which is variable over time. In addition, it is proportional to the Sharpe ratio, inversely proportional to volatility. Finally, it depends on the sensitivity of the manager's preference to the state variable. It is shown that the optimal solution of the optimization program leads to a principle of separation and a principle of revision:

Separation theorem in $m+2$ funds. The optimal portfolios of all investors are dynamic combinations of the following same $m+2$ funds: risk-free assets 0 ; the optimal growth portfolio $\underline{\alpha} ; m$ fund $\underline{\alpha}_{1}, \cdots, \underline{\alpha}_{m}$, the kth fund $\underline{\alpha}_{k}$ being constructed in such a way that its profitability is locally (that is to say between $t$ and $t+\mathrm{d} t$ ) perfectly correlated with the variations of the kth variable of state $Y_{k}$.

Principle of revision of the sovereign fund wealth portfolio: The composition of each of the $m+1$ separator funds $\underline{\alpha}, \underline{\alpha}_{1}, \cdots, \underline{\alpha}_{m}$ is readjusted continuously (depending on $t$ and of $\underline{Y}(t))$ and the agents affect $m+2$ separator funds $0, \underline{\alpha}, \underline{\alpha}_{1}, \cdots, \underline{\alpha}_{m}$ weights that depend on their preferences and are changed continuously.

What exactly are the $m$ funds $\underline{\alpha}_{1}, \cdots, \underline{\alpha}_{m}$ ?

We have $k$ state variables, $k=1, \cdots, m$. We have a vector $\underline{Y}(t)$ of state variables with $\underline{Y}(t)=\left(Y_{1}(t), Y_{2}(t), \cdots, Y_{k}(t), \cdots, Y_{m}(t)\right)$. Suppose that at time $t$, the state variables $Y_{1}(t)$ and $Y_{5}(t)$ change, we add 2 coverage allocations $\underline{\alpha}_{1}$ and $\underline{\alpha}_{5}$. The fund $\underline{\alpha}_{1}$ is constructed in such a way that its profitability is perfectly correlated with the variations of the state variable $Y_{1}(t)$. The fund $\underline{\alpha}_{5}$ is constructed in such a way that its profitability is perfectly correlated with the variations of the state variable $Y_{5}(t)$. Here, a separation into 4 funds prevails. The optimal growth portfolio consists of a fixed ratio of risky assets (equities, bonds, etc.).

Proposition 1: The portfolio of any investor who maximizes a concave utility expectancy includes:

$>$ An allocation in the $\log$ portfolio $\underline{\alpha}$ which would be, with asset 0 , the only one present if the investor was myopic. This allocation is proportional to the risk tolerance of the investor: it is therefore homothetic to the tangent portfolio or still obtained as a combination of tangent portfolio and risk-free assets: it is therefore efficient in the mean-variance sense, on the horizon $\mathrm{d} t$. 
$m$ allocations in the hedge portfolios $\underline{\alpha}_{1}, \cdots, \underline{\alpha}_{m}$, intended to protect the non-myopic investor against the changes in economic conditions that would cloud the outlook for his future investments.

a position (short or long) on the monetary asset 0 which accommodates the allocations to the $m+1$ other separating funds, so that the sum of the weights is always equal to unity: $\alpha_{0}=1-\underline{\alpha}^{*} \underline{1}$.

Proposition 2: When the rate $r$ is constant and no state variable affects the coefficients $\mu$ and $\Sigma$ which are constant, the logarithmic portfolio is constant weight: $\underline{\alpha}=\Sigma \Sigma^{\prime-1}(\underline{\mu}-r \underline{1})$. The optimal weights for risky assets are: $\underline{\alpha}^{*}=\tau(X(t)) ; \underline{\alpha}$ and $\underline{\alpha}^{*}$ are therefore proportional to the relative risk tolerance of the investor.

Since the number of state variables $m$ is zero, a separation into two funds prevails: all optimal portfolios are combinations of the risk-free asset and the logarithmic portfolio; the risky components of all the optimal portfolios have an identical structure: they are homothetic with $\underline{\alpha}$, thus the tangent portfolio, as in the static case studied by Markowitz or the dynamic case without revision.

Proposition 3: When a single state variable, the interest rate $r(t)$ affects the coefficients $\mu$ and $\Sigma$, a separation into three funds prevails: the monetary asset, the logarithmic portfolio and a perfectly correlated portfolio (positively or negatively) with changes in the interest rate $r(t)$ : a bond portfolio. In this case, the model is written as:

$$
\mathrm{d} r=\phi(t, r) \mathrm{d} t+\underline{q^{\prime}}(t, r) \mathrm{d} \underline{W} ; \underline{\mathrm{d}} \underline{R}=\underline{\mu}(t, \underline{r}) \mathrm{d} t+\Sigma(t, \underline{r}) \mathrm{d} \underline{W}
$$

here, $m=1$ and a separation into three funds prevails.

Proposition 4: When a single state variable, the stock market index affects the coefficients $\mu$ and $\Sigma$, a separation into three funds prevails: the monetary asset, the logarithmic portfolio and a perfectly correlated portfolio (positively or negatively) with the changes in the interest rate $r(t)$ : an index fund.

Results: We summarize here the theoretical results obtained, which we confront with the stylized facts:

$\checkmark$ R1: The model with revision requires the sovereign fund portfolio to have hedge funds while in the non-hedge model, the portfolio does not display hedge funds. This is in line with the stylized fact FS5.

$\checkmark$ R2: The models with revision show that the dynamic allocation follows the principle of separation of funds: the share of risk-free assets (monetary assets, for example) in the sovereign fund portfolio differs according to the risk profile of the fund. Indeed, stabilization funds that have a medium-term horizon tend to invest in liquid assets and relatively less risky asset classes; and generational savings funds with a long-term horizon tend to invest in relatively riskier asset classes with higher returns. The ratio of riskier assets to less risky assets is therefore lower in stabilization funds than in generational savings funds. This is in sync with the stylized fact FS4.

$\checkmark$ R3: On the other hand, the ratio of bonds to shares prevailing in the risky fund is identical regardless of the risk attitude (risk profile) of the fund. This 
theoretical result is in contradiction with the stylized fact FS3.

Thus, the Merton dynamic model that we used to formalize the strategic allocation of SWFs does not replicate all the stylized facts highlighted. Which dynamic theoretical model is likely to reproduce all the stylized facts, thus making it possible to explain the practice of the strategic allocation of the sovereign wealth funds?

Because sovereign wealth funds have risky asset ratios that are dependent on the risk profile of the investing state, they can be likened to profiled funds or lifestyle funds. These are diversified funds that depend on the risk attitude of the investor (lifestyle of the investor). The contradiction between the standard portfolio theory and the presence of profiled funds in the concrete practice of portfolio managers has been described as an enigma [24], especially since the use of profiled funds is a rule of common sense. Several attempts at explanation have been made: behavior that does not comply with the mean-variance criterion; absence of risk-free assets, due to a risk to the inflation rate which makes the real profitability of the monetary asset uncertain; taking into account non-liquid assets and investment horizon $T$ greater than the duration of the monetary assets; etc. But all these explanations proved to be disappointing, showing that this enigma cannot be removed by a simple relaxation of the assumptions of the traditional models of Markowitz (static case) and Merton (dynamic case).

\subsection{A Dynamic Model of Allocation of Sovereign Funds in Terms of Lifestyle Portfolio}

Bajeux-Besnainou, Jordan and Portait [1] show that the contradiction between lifestyle portfolio and standard portfolio theory is only apparent. In other words, when considering medium or long-term investments ( $T>1$ year), for which the money fund becomes risky because of the uncertainty affecting future short-term rates, by admitting revisions between 0 and $T$, they show that profiled funds can be explained by a dynamic optimization model at Merton. They solve the enigma. The strategy for allocating profiled funds is of the constant mix type. There are typically three types of investors: the conservative investor (C), the moderate investor $(\mathrm{M})$ and the aggressive investor $(\mathrm{A})$. Each of these investors has a lifestyle portfolio:

$\checkmark$ Conservative funds (P): investors who favor security will invest in bonds and monetary assets (conservative investor).

$\checkmark$ Balanced funds (E): those who want both a substantial return and a lower risk than an index will also buy bonds (moderate investor).

$\checkmark$ Dynamic funds (D): “aggressive” investors requiring a high expectation of profitability (with high risk) will invest primarily in equities.

The logic of the lifestyle portfolio recommends that the ratio of monetary assets/total portfolio and the ratio of bonds to shares should increase with the risk aversion of the investor. Using the theoretical framework developed by Bajeux-Besnainou et al. [1], which considers a model with three assets: a money fund, a bond fund and an equity fund, it is possible to develop a dynamic alloca- 
tion model of sovereign wealth funds to explain the lifestyle portfolios that are stabilization funds and generational savings funds. Stabilization funds that have a medium-term horizon and tend to invest in liquid assets and relatively less risky asset classes are the preserve of conservative investors. Stabilization funds are thus similar to prudent funds. Generational savings funds that have a long-term horizon and tend to invest in relatively higher-risk, higher-yielding asset classes are the result of aggressive investors. Generational savings funds are similar to dynamic funds.

\section{Concluding Remarks}

Our objective in this paper was to propose a dynamic model of SWF portfolio allocation based on some stylized facts. We have shown that a traditional dynamic model of allocation of sovereign funds to the Merton [20] allows to explaining the stylized facts according to that, on the one hand, the shares of monetary assets in such funds grow with the risk aversion of the state-investor over time, and on the other hand, these funds include the presence or absence of hedge funds correlated to the financial situation according to whether or not they admit the portfolio revision. However, this model predicts a lower risk asset/riskier asset ratio for sovereign stabilization funds and generational savings sovereign funds, which is at odds with the stylized fact of a lower risk asset/riskier asset ratio, lower in stabilization funds than in generational savings funds. A dynamic model more compatible with the optimal allocation of sovereign wealth funds is inspired by the theoretical framework of Bajeux-Besnainou et al. [1].

This dynamic model interprets stabilization funds and generational savings funds as lifestyle portfolios in which the share of risk-free assets in the sovereign fund portfolio differs according to the risk profile of the fund. In doing so, the model makes it possible to overcome the shortcomings of the Bodie and Brière models [17] [18] [19], which certainly consider all the sources of public revenues and public expenditure of the sovereign, but do not make it possible to explain the difference of optimal allocation between sovereign stabilization funds and generational savings sovereign funds. However, it remains to build a model that explains the optimal allocation of sovereign funds by integrating both the theoretical framework of Bajeux-Besnainou et al. [1] and that of Bodie and Brière [17] [18] [19]. This is what we will tackle in the future work.

\section{Conflicts of Interest}

The author declares no conflicts of interest regarding the publication of this paper.

\section{References}

[1] Bajeux-Besnainou, I., Jordan, J.V. and Portait, R. (2001) An Asset Allocation Puzzle: Comment. American Economic Review, 91, 1170-1179.

[2] Raymond, H. (2009) The Effect of Sovereign Wealth Funds' Investments on Stock 
Markets. EconomiX Working Paper 38.

[3] Raymond, H. (2010) Sovereign Wealth Funds as Domestic Investors of Last Resort during Crises. International Economics, 123, 121-160.

https://doi.org/10.1016/S2110-7017(13)60016-5

[4] Butt, S., Shivdasani, A., Stendevad, C. and Wyman, A. (2008) Sovereign Wealth Funds: A Growing Global Force in Corporate Finance. Journal of Applied Corporate Finance, 20, 73-83. https://doi.org/10.1111/j.1745-6622.2008.00170.x

[5] Sun, X., Li, J., Wang, Y. and Clark, W.W. (2014) China's Sovereign Wealth Fund Investments in Overseas Energy: The Energy Security Perspective. Energy Policy, 65, 654-661. https://doi.org/10.1016/j.enpol.2013.09.056

[6] Mathis, J. (2002) Gestion d'actifs. Economica, Gestion.

[7] Aaron, C., Bilon, I., Galanti, S. and Tadjeddine, Y. (2007) Les styles de gestion de portefeuille: Existe-t-ils ? Document de travail.

[8] Bernstein, S., Lerner, J. and Schoar, A. (2013) The Investment Strategies of Sovereign Wealth Funds. Journal of Economic Perspectives, 27, 219-238. https://doi.org/10.1257/jep.27.2.219

[9] Chhaochharia, V. and Laeven, L. (2008) Sovereign Wealth Funds: Their Investment Strategies and Performance. CEPR Discussion Paper (6959).

[10] Dyck, A. and Morse, A. (2011) Sovereign Wealth Fund Portfolios. Working Paper (2011-003), University of Chicago, Chicago.

[11] Bortolotti, B., Fotak, V., Megginson, W. and Miracky, W.F. (2010) Quiet Leviathans: Sovereign Wealth Fund Investment, Passivity, and the Value of the Firm. Working Paper.

[12] Clark, G.L. and Monk, A.H. (2009) The Oxford Survey of Sovereign Wealth Funds' Asset Managers. Working Paper, University of Oxford, Oxford.

[13] Scherer, B. (2009) A Note on Portfolio Choice for Sovereign Wealth Funds. Financial Markets and Portfolio Management, 23, 315-327.

[14] Scherer, B. (2009) Portfolio Choice for Oil Based Sovereign Wealth Funds. Journal of Alternative Investments, 13, 24-34.

[15] Brown, A., Papaioannou, M. and Petrova, I. (2010) Macrofinancial Linkages of the Strategic Asset Allocation of Commodity-Based Sovereign Wealth Funds. IMF Working Paper 10/9, January.

[16] Martellini, L. and Milhau, V. (2010) Asset-Liability Management Decisions for Sovereign Wealth Funds. Edhec-Risk Institute Publication.

[17] Bodie, Z. and Brière, M. (2013) Sovereign Wealth and Risk Management: A New Framework for Optimal Asset Allocation of Sovereign Wealth. Amundi Working Paper WP-011-2011, 31 p.

[18] Bodie, Z. and Brière, M. (2014) Optimal Asset Allocation for Sovereign Wealth Funds: Theory and Practice. Bankers Markets and Investors, 128, 45-61.

[19] Bodie, Z. and Brière, M. (2014) Sovereign Wealth and Risk Management: A Framework for Optimal Asset Allocation of Sovereign Wealth. Journal of Investment Management, Q1, 45-61.

[20] Merton, R.C. (1969) Lifetime Portfolio Selection under Uncertainty: The Continuous-Time Case. Review of Economics and Statistics, 51, 247-257. https://doi.org/10.2307/1926560

[21] Samuelson, P.A. (1969) Lifetime Portfolio Selection by Dynamic Stochastic Programming. Review of Economics and Statistics, 51, 239-246. 
https://doi.org/10.2307/1926559

[22] Cox, J.C. and Huang, C.-F. (1989) Optimal Consumption and Portfolio Policies When Asset Prices Follow a Diffusion Process. Journal of Economy Theory, 49, 33-83. https://doi.org/10.1016/0022-0531(89)90067-7

[23] Karatzas, I., Lehoczky, J.P. and Shreve, S.E. (1987) Optimal Portfolio and Consumption Decisions for a Small Investor on a Finite Horizon. SIAM Journal of Control and Optimization, 25, 1557-1586. https://doi.org/10.1137/0325086

[24] Canner, N., Mankiw, N.G. and Weil, D.N. (1997) An Asset Allocation Puzzle. American Economic Review, 87, 181-191. 